\title{
The Spanish adaptation of ANEW (Affective Norms for English Words)
}

\author{
Jaime Redondo, Isabel Fraga, Isabel Padrón, and Montserrat Comesaña \\ University of Santiago de Compostela, Santiago de Compostela, Spain
}

\begin{abstract}
This article presents the Spanish adaptation of the Affective Norms for English Words (ANEW; Bradley \& Lang, 1999). The norms are based on 720 participants' assessments of the translation into Spanish of the 1,034 words included in the ANEW. The evaluations were done in the dimensions of valence, arousal and dominance using the Self-Assessment Manikin (SAM). Apart from these dimensions, five objective (number of letters, number of syllables, grammatical class, frequency and number of orthographic neighbors) and three subjective (familiarity, concreteness and imageability) psycholinguistic indexes are included. The Spanish adaptation of ANEW can be downloaded at www.psychonomic.org.
\end{abstract}

The Affective Norms for English Words (ANEW; Bradley \& Lang, 1999a) provide a set of normative evaluative ratings for 1034 words in the English language. The ANEW complements previous work developed by the Center for Emotion and Attention (CSEA, University of Florida), such as the International Affective Digitized Sounds (IADS; Bradley \& Lang, 1999b) and the International Affective Picture System (IAPS; Lang, Bradley, \& Cuthbert, 1999).

The theoretical position assumed in these works falls inside the framework of the dimensional perspective of emotions (e.g., Bradley, 1994; Lang, 1995; Lang, Dhillon, \& Dong, 1995). This perspective, already defended by Wundt (1896), is based on work by Osgood (Osgood, Suci, \& Tanenbaum, 1957) and conceptualizes emotion as having three basic underlying dimensions along which the entire range of human emotions can be arranged. The two primary dimensions are valence (which ranges from pleasant to unpleasant) and arousal (which ranges from calm to excited). The third dimension, not as often mentioned because of its lesser consistency, is "dominance" or "control" (ranging from in control to out of control).

To evaluate a stimulus in these three dimensions, Lang (1980) developed a nonverbal pictographic measure: the Self-Assessment Manikin (SAM; see Figure 1). In the valence dimension, SAM ranges from "pleasant" (represented by a happy figure) to "unpleasant" (represented by a frowning figure). In the arousal dimension, the SAM ranges from "excited" (represented by a figure with overtly open eyes) to "calm" (represented by a sleepy figure). Lastly, the dominance dimension ranges from "out of control" (represented by a huge figure) to "in control" (represented by a tiny figure).

These normalized stimuli databases (i.e., IADS, IAPS, and ANEW) are a powerful work tool in investigation, as they make the replication of results and scientific commu- nication easier. On the other hand, they make it possible to conduct comparative studies with different categories of stimuli and sensorial modalities. Thus, the words in the ANEW have been used as stimuli in such diverse investigations as the analysis of neural correlates of emotion (e.g., Hamann \& Mao, 2002; Lewis, Critchley, Smith, \& Dolan, 2005), the study of activity in facial muscles (Larsen, Norris, \& Cacioppo, 2003), the effects of emotion on memory in youngsters and older adults (e.g., Kensinger, Briedly, Medford, Growdon, \& Corkin, 2002; Kensinger \& Corkin, 2002, 2003), or in investigations on political cognition and attitudes (e.g., Lodge \& Taber, 2005). Of the three instruments developed by the CSEA (i.e., IADS, IAPS, and ANEW), to date, only the IAPS has been adapted to Spanish (Moltó et al., 1999). Although recent standardized databases of the Spanish language which include objective and subjective indexes exist (LEXESP, Sebastián-Gallés, Martí, Carreiras, \& Cuetos, 2000; B-Pal, Davis \& Perea, 2005) none of them include the dimensions of valence, arousal and dominance as subjective indexes of affective character. ${ }^{1}$ The wide range of application of the ANEW, along with the aforementioned advantages of this database, made it necessary to adapt it to Spanish, a language that is spoken by more than 400 million people worldwide.

Apart from the ratings of each word in the three affective dimensions, the American standardization of the ANEW includes word frequency (Bradley \& Lang, 1999a). This is the only psycholinguistic index offered by the authors. However, it is often necessary to control other psycholinguistic indexes. For example, if one tries to use the words in this database as stimuli in a reaction time (RT) task, one needs to control (as well as frequency) for variables such as length and neighborhood because, as is well known, they affect RTs (see Álvarez, Alameda, \& 

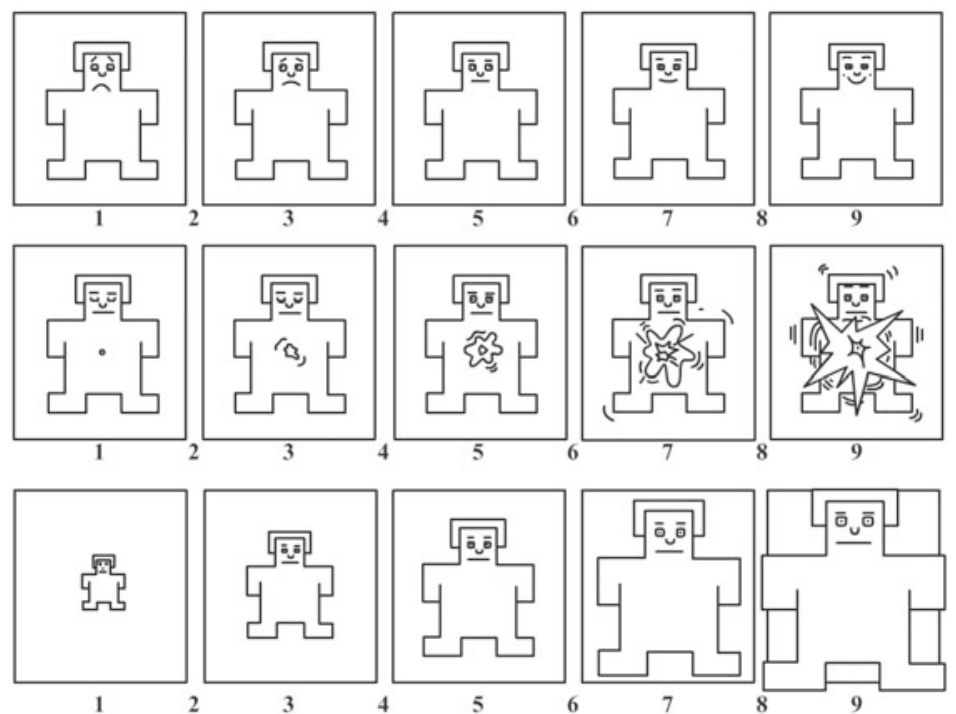

Figure 1. Self-Assessment Manikin (SAM). Self-evaluation scales for the dimensions of valence, arousal, and dominance.

Domínguez, 1999, for a brief review). Even the subjective indexes can be of high interest in the investigation. Thus, Altarriba and Bauer (2004) found that emotion words activate different levels of concreteness and imageability in the conceptual representation system of the subject. This way, emotion words are more imageable but less concrete than abstract words and, otherwise, less imageable and less concrete than the concrete words themselves. Thus, values are given of a series of psycholinguistic variables compiled from the databases LEXESP (Sebastián-Gallés, Martí, Carreiras, \& Cuetos, 2000) and BuscaPalabras (Davis \& Perea, 2005). In particular, objective indexes (number of letters, number of syllables, grammatical class, ${ }^{2}$ frequency and orthographic neighbors) as well as subjective indexes (familiarity, concreteness and imageability) are included.

\section{METHOD}

\section{Participants}

A total of 720 participants (560 women and 160 men), psychology students ranging in age from 18 to 25 years old (mean $=21.5$, $S D=1.81)$, contributed to the final data. The ratings of the words were obtained throughout the 2003-2004 and 2004-2005 academic years in different faculties of Psychology (or similar degrees) from several Spanish universities. ${ }^{3}$

\section{Materials and Procedure}

The words included in the database were obtained from the translation to Spanish of the 1,034 words in the original ANEW (Bradley \& Lang, 1999a). This translation was done by a professional philologist specializing in the English language. Then, the list of words was revised by an English philology professor and psycholinguistics researcher under the supervision of the authors. Once the 1,034 words had been translated, three random forms were created. Thus, each form contained the same 1,034 words, but in a different order. Because the evaluation of such a vast number of words would have been tedious for the subject, each form was divided in eight "answer sheets." Each answer sheet contained an average of 129 words which were evaluated by the subject in the three emotional dimensions (valence, arousal and dominance).

In order to make the assessments, a paper-and-pencil version of the SAM (see Figure 1) was used. It had been adapted from the ScanSAM used by Bradley and Lang (1999) in their normative study. Therefore, just as in this study, the subjects could evaluate each word in a 9-point rating scale for each dimension.

The assessments were done collectively in a classroom. Each subject received an answer sheet containing the words to be evaluated, an instruction sheet and a sheet with the SAM. After reading the instructions and before evaluating the words, any doubts were solved and six words were used as examples to give the subject a series of basic references before starting the assessment. ${ }^{4}$ The experimenters were psychologists with previous knowledge of the investigation, and were present during the whole session to resolve any doubts.

\section{Description of the Database}

The ratings of the words in each of the three affective dimensions are included in the appendix, along with the aforementioned psycholinguistic indexes. The database is organized in the following way:

Number: A number which identifies each of the 1,034 words and which corresponds to the original number in the ANEW (Bradley \& Lang, 1999).

English word: E-word is the noun of the original word in the ANEW database.

Spanish word: S-word is the noun of each word included. These words are in alphabetical order.

Affective assessments: The mean values $(M)$ and the standard deviation $(S D)$ for valence (Val), arousal (Aro), and dominance (Dom) are included. Data of the global sample (All) appear first, followed by data corresponding to females (Fem) and males (Mal).

Psycholinguistic indices:

(1) Objective indices:

- Number of letters: The Nlett variable is the number of letters in each word.

- Number of syllables: The Nsyll is the number of syllables in each word. This index was established according to the rules of the Real Academia de la Lengua 
Española (Royal Academy of the Spanish Language; RAE, 2001).

- Grammatical class: The GClass variable classifies the words by their grammatical role in spelling: ${ }^{5}$ noun $(\mathrm{N})$, adjective (A), and verb (V).

- Frequency: Freq is the number of occurrences of each type per million words (LEXESP; Sebastián-Gallés et al., 2000).

- Number of orthographic neighbors (Neigh): Two words are considered orthographic neighbors when they share all the letters (in the same position) except one (Coltheart, Davelaar, Jonasson, \& Besner, 1977; Davis \& Perea, 2005). ${ }^{6}$

(2) Subjective indices (all of them taken from LEXESP; SebastiánGallés et al., 2000): ${ }^{7}$

- Familiarity: The Fam variable refers to the subjective estimation of the degree of familiarity of a word, 1 being minimum familiarity and 7 the maximum.

- Concreteness: The Con variable refers to the subjective estimation of the degree of concreteness of a word, 1 being minimum concreteness and 7 the maximum.

- Imaginability: The Imag variable refers to the subjective estimation of the degree of imageability of a word, 1 being minimum familiarity and 7 the maximum.

\section{RESULTS AND DISCUSSION}

Figure 2 shows the distribution of the word ratings in the affective space defined by the dimensions of valence and arousal, both for men and for women. This distribution fits the typical boomerang shape found by Bradley and Lang (1999a) in their normative study and which also appears in other works (Figure 1 in Moltó et al., 1999, p. 62; Bradley \& Lang, 1999a, p. 49). In fact, a high quadratic correlation was found between valence and arousal $(R=.522, p<.000)$, which represents $27.1 \%$ of the variance (the lineal correlation between both dimensions only accounted for $2.22 \%$ of the variance). This datum is slightly lower than that found by Moltó et al., which was $R=.64$.

As can be seen in Figure 2, unpleasant words (low valence) are grouped in the lower right-hand area of the graph. Thus, the lower the valence of a word, the higher its arousal. This negative valence-arousal relation is normally found (e.g., Moltó et al., 1999, p. 63) in everyday life. Thus, the words which are most unpleasant for us tend to increase our level of arousal. For example, the word violación (rape) was rated with a very low valence (1.11) and a high arousal (7.98). On the other hand, the majority of the pleasant words (high valence) are found in the upper right-hand area of the graph, indicating that they possess a high level of arousal, that is, words which are more pleasant also tend to increase our level of arousal. For example, the word orgasmo (orgasm) was evaluated with a valence of 8.06 and an arousal of 8.16. Finally, the majority of the words with an intermediate valence were also evaluated with an intermediate or neutral level of arousal (e.g., botella [bottle], valence: 5.10; arousal: 4.68). This result also reflects our experience because neutral valence words do not usually vary our level of arousal.

The comments made above are based on the trend generally found. But the advantage of the bidimensional perspective is that it also allows us to select words which do
Table 1

Linear Correlations Between American and Spanish Ratings in the Three Affective Dimensions

\begin{tabular}{lccc}
\hline & All Subjects & Females & Males \\
\hline Valence & .916 & .867 & .920 \\
Arousal & .746 & .610 & .723 \\
Dominance & .720 & .539 & .721 \\
\hline
\end{tabular}

Note $-p<.001$ in all cases.

not align themselves with this tendency. For instance, one could choose pleasant words with neutral arousal (e.g., madre [mother], valence: 8.19; arousal: 5.19) and/or unpleasant words with intermediate arousal (e.g., funeral [funeral], valence: 1.48; arousal: 5.06).

We also tried to find if cultural differences exist between the American and the Spanish populations in the assessments of the words contained in the ANEW. With this aim, Pearson's correlation coefficients were calculated between the American and the Spanish ratings in both dimensions (see Table 1).

As can be seen, there is a high statistical significance in all the correlations obtained. The highest correlation is obtained in the valence dimension, followed by arousal and dominance. This pattern is kept both for the global sample as well as for males and females considered separately. This result suggests that the ANEW words are understood in a similar way by both Americans and Spaniards, and is similar to that which is observed using images (IAPS) by Bradley et al. (1993) with respect to other European countries and by Moltó et al. (1999) with respect to the Spanish population. We have also compared the means of the Spanish and the American ratings (Table 2), ${ }^{8}$ since Moltó et al. obtained significant differences in some affective dimensions when making this comparison.

First, the existence of statistical differences between the means of the Spanish and American ratings in the three emotional dimensions is remarkable. Second, the direction of these differences is similar for the global sample, and for female and male subjects separately. With respect to valence, the Americans tend to rate the ANEW words higher than the Spaniards. However, Moltó et al. (1999) did no find any significant differences in this dimension, neither globally nor as regards gender. Therefore, this result seems to be due to the type of stimulus used (IAPS pictures vs. ANEW words). Regarding the arousal dimension, the ANEW words were rated as more activating by Spanish subjects than by American ones. Moltó and his coworkers also obtained this result, which they interpreted

Table 2

Mean Values of the Spanish and American Populations' Ratings, by All Subjects and by Females and Males Separately, in the Three Affective Dimensions

\begin{tabular}{|c|c|c|c|c|c|c|}
\hline \multirow[b]{2}{*}{ Dimension } & \multicolumn{2}{|c|}{ All Subjects } & \multicolumn{2}{|c|}{ Females } & \multicolumn{2}{|c|}{ Males } \\
\hline & Spain & $\overline{\mathrm{USA}}$ & Spain & $\overline{\text { USA }}$ & Spain & $\overline{\text { USA }}$ \\
\hline Valence & 4.74 & 5.15 & 4.74 & 5.08 & 4.74 & 5.24 \\
\hline Arousal & 5.52 & 5.12 & 5.54 & 5.16 & 5.49 & 5.07 \\
\hline Dominance & 4.67 & 5.00 & 4.67 & 4.92 & 4.67 & 5.12 \\
\hline
\end{tabular}

Note $-p<.001$ in all the Spain-USA comparisons in each dimension. 


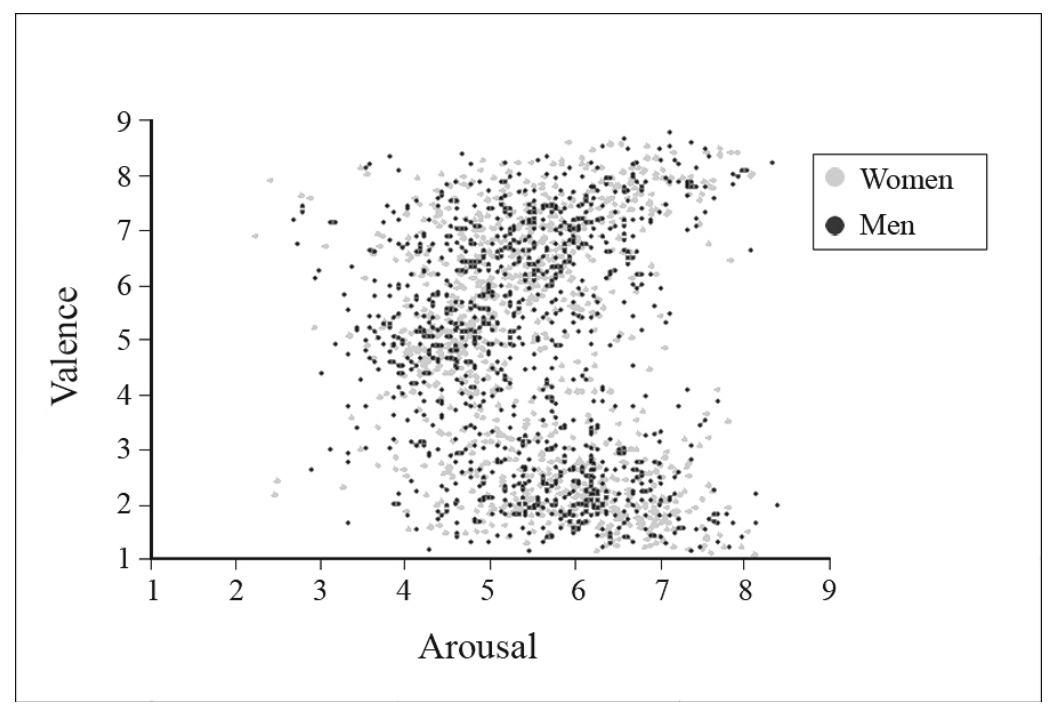

Figure 2. Distribution of the mean values (men and women) corresponding to the ratings of the 1,034 words in the dimensions of valence and arousal.

in terms of a higher emotional reactivity in Spanish subjects. Lastly, the American subjects obtained higher values than the Spanish ones in the dominance dimension. As before, this result was also obtained with images (IAPS) by Moltó et al., suggesting that Americans possess a higher perception of control relative to affective stimuli, be they words or images.

We were also interested in looking for differences which are due to gender in the assessments of the words obtained in our normative study. The distribution of assessments in the affective space (see Figure 2) for both men and women is very similar. Thus, the quadratic correlation between valence and arousal was $R=.526, p<.000$, for females, and $R=.443, p<.000$, for males. These values were lower than those obtained in the Spanish adaptation of the IAPS (.65 and .61 for women and men, respectively). No statistically significant differences were found in the mean ratings by men and women in none of the three dimensions (Table 3).

Pearson's correlation between the ratings of men and women was $R=.973$ for valence, $R=.843$ for arousal, and $R=.840$ for dominance ( $p<.000$ in all three cases). Furthermore, the ranges of ratings for men and women did not differ considerably. These results are different to those obtained from the study by Molto and his coworkers using IAPS. Thus, on the one hand these authors found that the average arousal and dominance was significantly higher for women than for men. On the other hand, women used a higher range of values than men in all dimensions. Therefore, in the Spanish population the female-male differences found in the assessments of the IAPS images disappear when participants rate words from the ANEW.

To sum up, our work has been developed under the framework of the dimensional perspective of emotion, from which it is assumed that emotion can be characterized as having, at least, two orthogonal dimensions: valence and arousal. In order to measure and control these two dimensions reliably, standardized stimuli databases are needed. IAPS, IADS, and ANEW are good examples of this kind of instruments. The study we present here is the result of adapting ANEW to the Spanish language in a Spanish population. As well as in the original ANEW (Bradley \& Lang, 1999a), we have used SAM, a standard assessment system whose effectiveness for rating affective states has been proved (Bradley \& Lang, 1994). But we have gone further, including a set of psycholinguistic variables that are well-known to be crucial for word processing. Moreover, the control of these types of variables is highly relevant if we take into account that emotion words seem to have their own representational status, at least with regards to their level of abstraction and degree of imageability (Altarriba \& Bauer, 2004).

Therefore, as well as the original ANEW, the availability of its Spanish adaptation will contribute to improve research in many different domains, both classic and recent. For example, with regard to classic conditioning, the words with high values for valence and arousal in the ANEW could be used as unconditioned appetitive stimuli. As typical aversive unconditioned stimuli, unpleasant words with a high level of arousal could be used. Finally, neutral stimuli that can act as conditioned stimuli could be those words with intermediate values in both dimensions. Also, the bidimensional approach assumed in the ANEW base allows one to take into consideration the arousal di-

Table 3

Means, Standard Deviations (SDs), and Ranges of the Spanish Ratings for Men and Women Corresponding to the Three Affective Dimensions

\begin{tabular}{lccccccc}
\hline & \multicolumn{3}{c}{ Females } & & \multicolumn{3}{c}{ Males } \\
\cline { 2 - 4 } \cline { 6 - 8 } Dimension & $M$ & $S D$ & Range & & $M$ & $S D$ & Range \\
\hline Valence & 4.74 & 2.16 & 7.51 & & 4.74 & 2.11 & 7.65 \\
Arousal & 5.54 & 1.02 & 5.87 & & 5.49 & 1.05 & 5.70 \\
Dominance & 4.67 & 1.09 & 5.79 & & 4.67 & 1.07 & 6.10 \\
\hline
\end{tabular}


mension for affective priming and evaluative conditioning research. In these kinds of studies, it was well known that the time to evaluate a target stimulus as positive or negative varies depending on whether the prime and target stimuli share the same valence or not (e.g., Bargh, Chaiken, Govender, \& Pratto, 1992; Hermans, de Houwer, $\&$ Eelen, 2001). However, the role of arousal has been rather neglected, and, as we have pointed out before, the same level of valence can correspond to different levels of arousal. Another line of research where ANEW would be of great interest is the study of the attentional resources dedicated to the processing of emotion words as a function of their situation in affective space (Fraga, Redondo, Piñeiro, \& Alcaraz, 2007). Finally, the Spanish ANEW adaptation that is presented here will allow one to carry out cross-linguistic studies (see, e.g., Campos \& Astorga, 1988; Harris, Aycicegi, \& Gleason, 2003), comparing for instance English and Spanish while using the same words, or even studying bilingual subjects' processing of emotion words in both languages. In conclusion, the database presented here will be very useful to researchers, as it will allow them to study links between cognition and emotion more reliably.

\section{AUTHOR NOTE}

This work was supported by Grant PGIDIT-03PXIA20401PR from the Galician government. The authors are especially grateful to Carlos Acuña Fariña for his great help throughout the whole process of the Spanish adaptation of ANEW. We also thank Margaret Bradley, who provided us with the ANEW; Manuel Perea, Javier García-Orza, José L. Marcos, and Mar Bernal for their help in data collection; and Ana Piñeiro and Martiño Rodríguez for their work with registration and computer processing of word ratings. Correspondence concerning this article should be addressed to J. Redondo, Facultad de Psicología, Universidade de Santiago de Compostela, 15706 Santiago de Compostela, Spain (e-mail: jredondo@usc.es).

\section{REFERENCES}

Altarriba, J., \& Bauer, L. M. (2004). The distinctiveness of emotion concepts: A comparison between emotion, abstract, and concrete words. American Journal of Psychology, 117, 389-410.

Álvarez, C. J., Alameda, J. R., \& Domínguez, A. (1999). El reconocimiento de las palabras: Procesamiento ortográfico y silábico [Word recognition: Orthographic and syllabic processing]. In M. de Vega \& F. Cuetos (Eds.), Psicolingüística del español [Spanish-language psycholinguistics] (pp. 89-130). Madrid: Trotta.

Bargh, J. A., Chaiken, S., Govender, R., \& Pratto, F. (1992). The generality of the attitude activation effect. Journal of Personality \& Social Psychology, 62, 891-912.

Bradley, M. M. (1994). Emotional memory: A dimensional analysis. In S. H. M. van Goozen, N. E. V. der Poll, \& J. A. Sergeant (Eds.), Emotions: Essays on emotion theory (pp. 97-134). Hillsdale, NJ: Erlbaum.

Bradley, M. M., \& LANG, P. J. (1994). Measuring emotion: The selfassessment manikin and the semantic differential. Journal of Behavioral Therapy \& Experimental Psychiatry, 25, 49-59.

Bradley, M. M., \& LANG, P. J. (1999a). Affective norms for English words (ANEW): Instruction manual and affective ratings. Gainesville, FL: Center for Research in Psychophysiology, University of Florida.

BRADLEY, M. M., \& LANG, P. J. (1999b). International affective digitized sounds (IADS): Stimuli, instruction manual and affective ratings. Gainesville, FL: Center for Research in Psychophysiology, University of Florida.

CAmpos, A., \& Astorga, V. M. (1988). Abstractness and emotional values for French and Spanish words. Perceptual \& Motor Skills, 66, 649-650.

Center for the Study of Emotion and Attention [CSEA-NIMH] (1999). The international affective picture system: Digitized photo- graphs. Gainesville, FL: Center for Research in Psychophysiology, University of Florida.

Coltheart, M., Davelaar, E., Jonasson, J. T., \& Besner, D. (1977). Access to the internal lexicon. In S. Dornic (Ed.), Attention and performance VI (pp. 535-555). Hillsdale, NJ: Erlbaum.

Davis, C. J., \& Perea, M. (2005). BuscaPalabras: A program for deriving orthographic and phonological neighborhood statistics and other psycholinguistic indices in Spanish. Behavior Research Methods, 37, 665-671.

Fraga, I., Redondo, J., Piñeiro, A., \& Alcaraz, M. (2007). Attentional processing of emotional words. Manuscript in preparation.

Hamann, S., \& MaO, H. (2002). Positive and negative emotional verbal stimuli elicit activity in the left amygdala. NeuroReport, 13, 15-19.

Harris, C., L., Aycicegi, A., \& Gleason, J. B. (2003). Taboo words and reprimands elicit greater autonomic reactivity in a first language than in a second language. Applied Psycholinguistics, 24, 561-579.

Hermans, D., De Houwer, J., \& Eelen, P. (2001). A time course analysis of the affective priming effect. Cognition \& Emotion, 15, 143-165.

Kensinger, E. A., Briedly, B., Medford, N., Growdon, J. H., \& Corkin, S. (2002). Effects of normal aging and Alzheimer's disease on emotional memory. Emotion, 2, 118-134.

Kensinger, E. A., \& CORKIN, S. (2002, March). Recollection benefit for negative words in young and older adults. Poster presented at the Eastern Psychological Association Meeting, Boston.

Kensinger, E. A., \& Corkin, S. (2003). Memory enhancement for emotional words: Are emotional words more vividly remembered than neutral words? Memory \& Cognition, 31, 1169-1180.

LANG, P. J. (1980). Behavioral treatment and bio-behavioral assessment: Computer applications. In J. B. Sidowski, J. H. Johnson, \& T. A. Williams (Eds.), Technology in mental health and delivery systems (pp. 119-137). Norwood, NJ: Ablex.

Lang, P. J. (1995). The emotion probe. American Psychologist, 50, 372-385.

LANG, P. J., Bradley, M. M., \& Cuthbert, B. N. (1999). International affective picture system (IAPS): Technical manual and affective ratings. Gainesville, FL: Center for Research in Psychophysiology, University of Florida.

Lang, A., Dhillon, P., \& Dong, Q. (1995). Arousal, emotion, and memory for television messages. Journal of Broadcasting \& Electronic Media, 38, 1-15.

Larsen, J. T., Norris, C. J., \& CACioppo, J. T. (2003). Effects of positive and negative affect on electromyographic activity over zygomaticus major and corrugator supercilii. Psychophysiology, 40, 776-785.

Lewis, P. A., Critchley, H. D., Smith, H. D., \& Dolan, R. J. (2005). Brain mechanisms for mood congruent memory facilitation. NeuroImage, 25, 1214-1223.

LODGE, M., \& TABER, C. S. (2005). The automaticity of affect for political leaders, groups, and issues: An experimental test of the hot cognition hypothesis. Political Psychology, 26, 455.

Moltó, J., Montañés, S., Poy, R., Segarra, P., Pastor, M. C., Tormo, M. P., ET AL. (1999). Un nuevo método para el estudio experimental de las emociones: El International Affective Picture System (IAPS). Adaptación española. Revista de Psicología General y Aplicada, 52, 55-87.

Osgood, C., Suci, G., \& Tannenbaum, P. (1957). The measurement of meaning. Urbana: University of Illinois.

Real Academia Española (2001). Diccionario de la lengua española [Spanish-language dictionary] (22nd ed.). Madrid: Espasa.

Redondo, J., Fraga, I., Comesaña, M., \& Perea, M. (2005). Estudio normativo del valor afectivo de 478 palabras españolas. Psicológica, 26, 317-326.

Sebastián, N., Martí, M. A., Carreiras, M. F., \& Cuetos, F. (2000). LEXESP: Léxico informatizado del español. Barcelona: Ediciones de la Universitat de Barcelona.

Wundt, W. (1896). Compendio de psicología. Madrid: La España Moderna.

\section{NOTES}

1. The B-Pal database includes the affective indexes of 478 Spanish words which are given in an earlier work (Redondo, Fraga, Comesaña, \& Perea, 2005).

2. Grammatical class is included here for the first time. 
3. University of Santiago de Compostela, University of A Coruña, University of Valencia, and University of Málaga.

4. The words, which obviously did not appear on the answer sheet, were: abuso (abuse), apasionante (passionate), ladrillo (brick), catástrofe (catastrophe), sexualidad (sexuality), and fiel (loyal, faithful). In a previous study (Redondo et al., 2005), these words were proved to represent different areas of the affective space.

5. In the majority of cases the word may be assigned to more than one category. The order in which they are collected reflects the information given by the Diccionario de la RAE (2001) (Dictionary of the Royal Academy of Spanish Language).

6 . The density of neighboring ties may differ widely (Redondo et al., 2005): "arroz" (rice) has only one orthographic neighbor ("atroz" [atrocious, cruel]), while "capa" (cape) has 20 orthographic neighbors ("lapa" [limpet], "mapa" [map], "tapa" [lid], "copa" [glass, cup], "cara" [face], etc.).

7. If the subjective index is not available the "UnAv" label is included.

8. Although Bradley and Lang (1999) do not report these values, we have calculated them from the normative data included in their study.

\section{ARCHIVED MATERIALS}

The following materials associated with this article may be accessed through the Psychonomic Society's Norms, Stimuli, and Data archive, www.psychonomic.org/archive/.

To access these files, search the archive for this article using the journal (Behavior Research Methods), the first author's name (Redondo), and the publication year (2007).

FILE: Redondo-BRM-2007.zip

DESCRIPTION: The compressed archive file contains two files:

RedondoEtAl(2007).txt, containing the Spanish adaptation of ANEW (Affective Norms for English Words).

RedondoEtAl(2007).xls, containing the same information in Excel spreadsheet format.

AUTHOR’s E-MAIL ADDRESS: j.redondo@usc.es.

(Manuscript received June 15, 2006; accepted for publication July 24, 2006.) 